
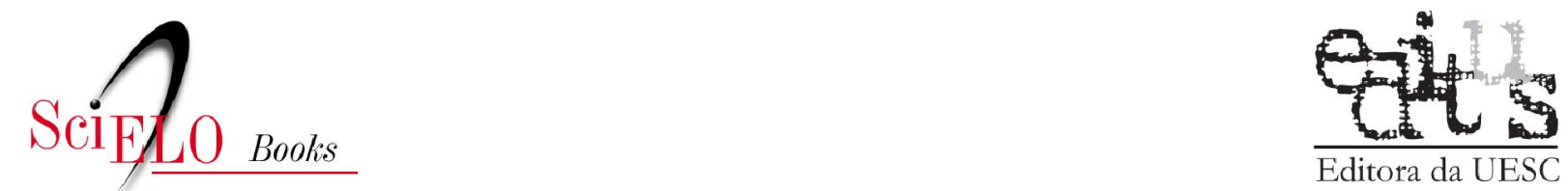

Editora da UESC

\title{
4 Legislação básica aplicada à recuperação ambiental
}

\author{
Danilo Sette de Almeida
}

SciELO Books / SciELO Livros / SciELO Libros

ALMEIDA, DS. Legislação básica aplicada à recuperação ambiental. In: Recuperação ambiental da Mata Atlântica [online].3rd ed. rev. and enl. Ilhéus, BA: Editus, 2016, pp. 32-39. ISBN 978-85-7455440-2. Available from SciELO Books $<\underline{\text { http://books.scielo.org }>\text {. }}$

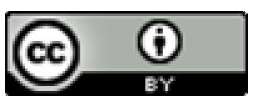

All the contents of this work, except where otherwise noted, is licensed under a Creative Commons Attribution 4.0 International license.

Todo o conteúdo deste trabalho, exceto quando houver ressalva, é publicado sob a licença Creative Commons Atribição 4.0.

Todo el contenido de esta obra, excepto donde se indique lo contrario, está bajo licencia de la licencia $\underline{\text { Creative }}$ Commons Reconocimento 4.0. 


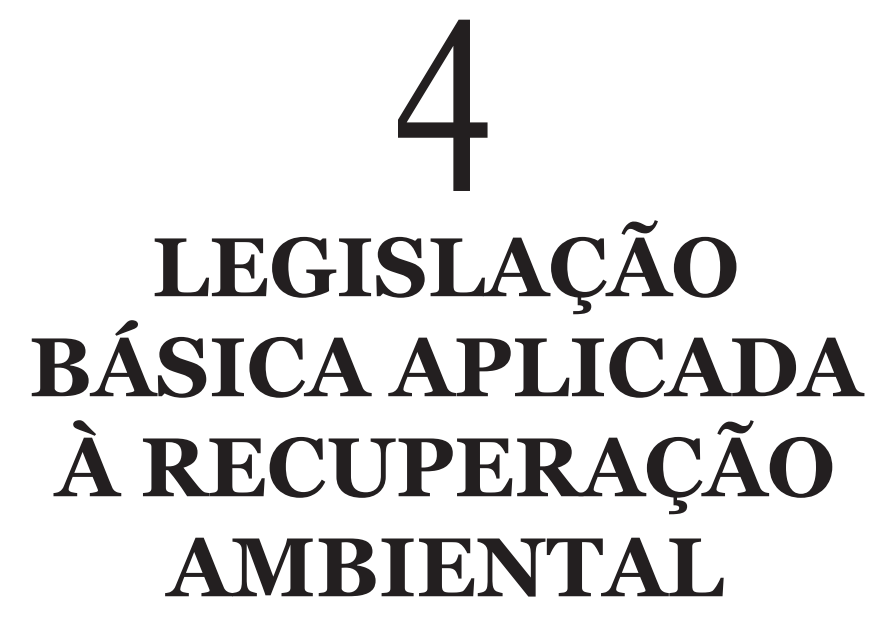




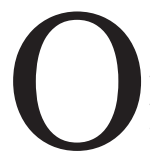

conhecimento sobre legislação ambiental aplicado à recuperação de áreas degradadas é considerado de fundamental importância para o técnico, que vai trabalhar nesta área na elaboração de projetos, pois existem dispositivos legais que normatizam o modo de apresentação dos projetos além de critérios técnicos mínimos a serem atendidos por cada projeto específico. Novos aparatos legais, como a Lei da Mata Atlântica e o novo Código Florestal de 2012, definem critérios para demarcação e recuperação das áreas de preservação permanente e reserva legal e, também, mecanismos, como a implantação do CAR - Cadastro Ambiental Rural e do PRA (Programa de Regularização Ambiental), dentro de cada propriedade, permitem, a partir deste marco legal, a demarcação de áreas, dentro do imóvel rural, onde será necessário o desenvolvimento das atividades de recuperação e de conservação ambiental. Apesar de que, no Brasil, estes dispositivos legais são recentes (primeiras leis sobre obrigatoriedade de se recuperar áreas degradadas datam do início da década de 1980). A legislação tem evoluído e hoje temos a obrigação legal de recuperação de áreas degradadas no que se refere à atividade minerária, florestas e demais formas de vegetação, situadas em áreas de preservação permanente e áreas de reserva legal (no domínio da Mata Atlântica corresponde a um percentual de $20 \%$ da área total do imóvel rural). Visando melhor orientação, discutiremos a legislação pertinente à recuperação de uma forma sucinta e prática, destacando os aspectos aplicados à parte técnica.

A legislação ambiental brasileira é considerada por especialistas em direito ambiental como sendo uma das melhores do mundo. Atualmente, todo empreendimento potencialmente impactante passa por um processo de licenciamento ambiental, em que são assumidos compromissos para adoção de medidas mitigadoras, visando o controle e a compensação ambiental desses impactos. A legislação prevê a participação popular neste processo, e possuímos recursos para responsabilizar e obrigar a todos os empreendimentos, que causem algum tipo de degradação ambiental, a apresentarem e executarem planos de reparação e compensação dos danos provocados. Entretanto falta uma maior participação popular em todo este processo, como também maior interesse dos órgãos públicos envolvidos na implementação de um sistema eficaz de controle e fiscalização, penalizando abusos contra o meio ambiente. Podemos observar, em várias 
regiões do Brasil, louváveis ações do Ministério Público estimulando ações práticas e eficazes de recuperação ambiental.

De uma forma bastante resumida, passamos a descrever as principais leis aplicadas:

1. Lei Federal 6938/81 - Lei de Política Nacional de Meio Ambiente - primeira lei no sentido de realmente organizar a política de meio ambiente e toda a estrutura governamental - no nível federal, estadual e municipal -, ligada aos assuntos ambientais. Criou o CONAMA e o SISNAMA (regulamentados pelo Decreto n. 88.351, de o1 junho de 1983), define como degradação da qualidade ambiental qualquer alteração adversa das características e elementos que integram o meio ambiente.

2. Lei Federal 7.347/85 - considerada como um grande avanço em termos de participação popular em ações relativas ao meio ambiente. Prevê ação civil pública, criando instrumentos que permitem a defesa do meio ambiente na esfera jurisdicional. Cria instrumentos para viabilizar a recuperação de áreas degradadas, através de um fundo específico e de licitação para contratação de empresa para recuperação de áreas degradadas.

3. Resolução CONAMA n. oo1/86 - estabelece critérios básicos e diretrizes gerais para o Estudo de Impacto ambiental (EIA) e Relatório de Impacto Ambiental (RIMA). Para determinados tipos de empreendimentos exige-se a realização prévia do EIA e RIMA, onde são realizados diagnósticos e planejadas ações de minimização de impactos e mitigação de prováveis danos ambientais.

4. Constituição Federal de 1988 - Artigo 225 - a floresta atlântica é considerada patrimônio nacional e sua utilização se fará, na forma da lei, dentro de condições que assegurem a preservação do meio ambiente, inclusive quanto ao uso dos recursos naturais. Consolida os instrumentos já existentes, e, a partir da Carta, temos a criação de novos institutos que são aplicáveis na proteção ambiental (ação popular, mandato de segurança 
coletivo e o mandato de injunção), além de dar maior respaldo para os mecanismos já existentes. No seu parágrafo terceiro, esta lei informa a necessidade de reparar os danos ambientais (independente das sanções penais e das multas que possam incidir sobre as pessoas físicas e jurídicas responsáveis pela degradação).

5. Decreto-lei n. $\mathbf{9 7 . 6 3 2 / 8 9}$ - regulamentou a lei $n$. 6.938/81, obrigando a recuperação da área degradada como parte do Relatório de Impacto Ambiental. Instituiu o Plano de Recuperação de Áreas Degradadas (PRAD), que pode ser empregado de forma preventiva ou corretiva, para áreas degradadas por ações de mineradoras. Convém observar que nenhum estado possui legislação específica sobre Recuperação de Áreas Degradadas, complementar à legislação federal já existente. Uma medida interessante seria a ampliação da necessidade do PRAD para outras atividades, para que isto ocorra se faz necessária a ampliação da abrangência das leis por parte do estado, não penalizando somente o setor de mineração e de construção de rodovias, mas também a aplicação em outros setores potencialmente degradadores.

6. Lei Federal n. 9.605, de fevereiro de 1998 - Dispõe sobre sanções penais e administrativas derivadas de condutas e atividades lesivas ao meio ambiente, e dá outras providências. Através do art. 23, II, obriga o infrator a recompor o ambiente degradado. É a chamada lei dos crimes ambientais, que permite abertura de uma ação e processo penal contra crimes ambientais. Esta lei prevê penalidades como prestação de serviços à comunidade, interdição temporária de direitos, suspensão parcial ou total de atividades, prestação pecuniária e recolhimento domiciliar. A partir deste dispositivo legal, também foi criado o Termo de Ajustamento de Conduta (TAC), que é formalizado pelo órgão ambiental através do Ministério Público, com o cumprimento das obrigações estipuladas no TAC, traduzidas muitas vezes em ações de recuperação de áreas degradadas, o infrator pode conseguir uma redução de até $90 \%$ do valor da multa ambiental aplicada. 
7. Decreto n. 3.420, de abril de 2000 - cria o Programa Nacional de Florestas que fomenta a "recomposição e restauração de florestas de preservação permanente, de reserva legal e áreas alteradas".

8. Resolução CONAMA 387/o6, de 27/12/2006 - dispõe sobre licenciamento obrigatório de assentamentos rurais. Nesta resolução, estão previstas ações de recuperação ambiental de áreas degradadas, através da elaboração do Plano de Recuperação do Assentamento, onde é programada a recuperação de áreas de reserva legal e de preservação permanente.

9. Lei Federal n. 11.428, de dezembro de 2006 dispõe sobre a utilização e proteção da vegetação nativa do Bioma Mata Atlântica, e dá outras providências. Esta lei estabelece as medidas compensatórias para os casos de supressão de vegetação secundária em estágio avançado e médio de regeneração, quando a recuperação será de área equivalente à área do empreendimento, com as mesmas características ecológicas, na mesma bacia hidrográfica e, sempre que possível, na mesma microbacia hidrográfica. Esta lei prevê, em seu art. 10, que "O poder público fomentará o enriquecimento ecológico da vegetação do Bioma Mata Atlântica, bem como o plantio e o reflorestamento com espécies nativas, em especial as iniciativas voluntárias de proprietários rurais".

10. Decreto n. 6.660, de novembro de 2008 - regulamenta os dispositivos da Lei Federal da Mata Atlântica (11.428/2006). Este decreto, através de seu art. 12, faculta o plantio ou o reflorestamento com espécies nativas, sem necessidade de autorização do órgão ambiental competente, incluindo aí os plantios com finalidade de recuperação ambiental e com finalidade econômica. As espécies florestais nativas plantadas devem ser cadastradas junto ao órgão ambiental competente, o cadastramento permite o corte ou a exploração destas espécies nativas comprovadamente plantadas. $\mathrm{O}$ cadastramento deve ser realizado no prazo máximo de sessenta dias, após a realização do plantio ou do reflorestamento. 
Com referência à recuperação ambiental, este decreto prevê o plano de compensação ambiental que, para obtenção da autorização de supressão de vegetação de Mata Atlântica, o requerente deve

[...] destinar área equivalente à extensão da área desmatada, para conservação, com as mesmas características ecológicas, na mesma bacia hidrográfica, sempre que possível na mesma microbacia hidrográfica e, nos casos previstos nos arts. 30 e 31 da Lei ${ }^{0} 11.428$, de 2006, em áreas localizadas no mesmo Município ou região metropolitana (art. 26 do Decreto $\mathrm{n}$. $6.660 / 2008)$.

Conforme $\S 2^{\circ}$ deste mesmo art. 26 a

[...] execução da reposição florestal deverá seguir as diretrizes definidas em projeto técnico, elaborado por profissional habilitado e previamente aprovado pelo órgão ambiental competente, contemplando metodologia que garanta o restabelecimento de índices de diversidade florística compatíveis com os estágios de regeneração da área desmatada.

11. Instrução normativa n. 4, de 13 de abril de 2011 - esta instrução estabelece procedimentos para elaboração de Projeto de Recuperação de Área Degradada - PRAD ou Área Alterada. Esta instrução traz como anexos Termos de Referência e distingue dois tipos de PRAD (PRAD e PRAD simplificado), aplicados conforme cada caso especificado na norma. Na instrução, é determinado que "o PRAD deve reunir informações, diagnósticos, levantamentos e estudos que permitam a avaliação da degradação ou alteração e a consequente definição de medidas adequadas à recuperação da área”. Este dispositivo proposto pelo IBAMA orienta então como elaborar um PRAD para apresentação aos órgãos federais.

12. Lei Federal n. 12.651/12 - Novo Código Florestal - o novo Código Florestal prevê a recomposição gradual das áreas de reserva legal e recuperação das áreas de preservação permanente em diferentes faixas, confome o tamanho dos imóveis rurais. As áreas de 
preservação permanente e de reserva legal, que não possuem mais sua vegetação natural, são consideradas degradadas, portanto necessitam legalmente de serem recuperadas. Em seu artigo primeiro, o novo Código Florestal estabelece, em suas alíneas 6, 7 e 8, a responsabilidade comum de União, Estados, Distrito Federal e Municípios, em colaboração com a sociedade civil, na criação de políticas para a preservação e restauração da vegetação nativa e de suas funções ecológicas e sociais nas áreas urbanas e rurais, assim como a inovação para o uso sustentável e a recuperação, além de criação e mobilização de incentivos jurídicos e econômicos para fomentar a preservação e a recuperação da vegetação nativa.

A recuperação das áreas de Reserva Legal está prevista no artigo 17, do Código Florestal, onde temos: "deverá ser iniciado o processo de recomposição da Reserva Legal em até dois anos contados a partir da data da publicação desta Lei, devendo tal processo ser concluído nos prazos estabelecidos pelo Programa de Regularização Ambiental - PRA”. Também o art. 66, em seu parágrafo segundo, determina que a recomposição da área de reserva legal deverá ser concluída em até 20 (vinte) anos, abrangendo, a cada 02 (dois) anos, no mínimo 1/10 (um décimo) da área total necessária para sua complementação.

No capítulo X do novo Código Florestal, temos o programa de apoio e incentivo à preservação e recuperação do meio ambiente, no qual são mencionadas linhas de financiamento específicas assim como isenção de impostos e utilização de fundos públicos, também apoio técnico e financeiro (art. 58) e Programas de Regularização Ambiental - PRA (art. 59), onde estão previstas todas as estratégias de recuperação de áreas degradadas na propriedade rural.

Assim, vários dispositivos legais, principalmente o novo Código Florestal, incentivam a restauração de áreas degradadas, a necessidade de adequação ambiental dos imóveis rurais, conservando as áreas florestais existentes como reserva legal e áreas de preservação permanente e promovendo a recuperação de áreas degradadas é um mecanismo muito importante para conservação dos biomas brasileiros. 
Existem outros dispositivos legais relacionados à restauração florestal especificamente para os estados brasileiros, estes dispõem desde as compensações ambientais (alguns estados atrelam a liberação de desmatamento a plantios de restauração compensatórios com a mesma área ou maiores) até o estabelecimento e regras de plantios de restauração (número de espécies a serem utilizadas, percentagens de uso de espécies ameaçadas de extinção, número de espécies frutíferas etc.).

Para a Mata Atlântica, a recomposição/conservação das áreas de reserva legal e a preservação permanente podem significar a recuperação deste bioma. Considerando que, atualmente, mais de 70\% dos remanescentes de Mata Atlântica estão nas mãos de particulares, a criação de mecanismos que incentivem a recuperação de áreas degradadas (reservas legais ou preservação permanente) e conservação dos últimos remanescentes pode representar uma recuperação real de nossa floresta atlântica. 